\title{
Association of Birth Parameters with Refractive Status in a Sample of Caucasian Children Aged 4-17 Years
}

\author{
Berna Akova-Budak, ${ }^{1}$ Sertaç Argun Kivanç, ${ }^{1}$ and Osman Okan Olcaysü ${ }^{2}$ \\ ${ }^{1}$ Department of Ophthalmology, School of Medicine, Uludag University, 16059 Bursa, Turkey \\ ${ }^{2}$ Department of Ophthalmology, Erzurum Region Education and Training Hospital, 25240 Erzurum, Turkey \\ Correspondence should be addressed to Berna Akova-Budak; bernaakova@hotmail.com
}

Received 5 January 2015; Revised 17 March 2015; Accepted 1 April 2015

Academic Editor: Majid M. Moshirfar

Copyright ( 2015 Berna Akova-Budak et al. This is an open access article distributed under the Creative Commons Attribution License, which permits unrestricted use, distribution, and reproduction in any medium, provided the original work is properly cited.

Purpose. To investigate the association of birth parameters with refractive status in different age groups of Caucasian children. Materials and Methods. This cross-sectional study included 564 eyes of 282 children aged 4 to 17 years. All children underwent complete ophthalmologic examination. The children were divided into three groups according to their refractive status (emmetropia,myopia, and hyperopia), ages (4-7, 8-9, 10-12, and 13-17), and appropriateness for gestational age, respectively. Results. The mean age of the children was $9.2 \pm 2.8$ (age range $4-17$ years). The mean spheric equivalent was $+0.3 \pm 1.7$ (range: $(-10.0)-$ $(+10.0)$ diopters). The mean birth weight and gestational age were $2681.1 \pm 930.8$ grams (750-5000 grams) and $37.2 \pm 3.7$ weeks (25-42 weeks). According to multinominal logistic regression analysis, children with myopia were more likely to have higher birth weights than emmetropic children (OR: 1.0, 95\% CI: 1.000-1.001, and $P=0.028$ ). The hypermetropes were found to be significantly small for gestational age between 13 and 17 years of age. Conclusion. Birth weight and appropriateness for gestational age as birth parameters may have an impact on development of all types of refractive errors. The hypermetropic children tended to be small for gestational age.

\section{Introduction}

Full term newborn babies tend to be hypermetropic at birth $[1,2]$ whereas preterm babies have been found to be either hypermetropic or myopic; even very preterm babies with severe ROP are slightly hyperopic at birth [3-5].

To date, refractive status at birth and its relation to birth weight (BW), birth length, head circumference, and gestational age (GA) have been studied and refractive error has been reported to correlate better with birth weight more than it did with GA [6]. On the one hand, another study on preterms from 2 weeks to 6 months of age reported no correlation of refractive error to GA or BW [7].

Babies born prematurely, with low birth weight or with retinopathy of prematurity, usually develop myopia $[3,8]$. Numerous studies have been carried out to find out the relations of refractive error and ocular biometric measures with birth parameters in preterm or low birth weight child at birth and in the long term $[6,9-13]$. A few studies investigated the association of birth parameters and refraction or biometric parameters in the general population of children [14-16]. In this cohort study, we aimed to investigate the association of birth parameters (BW, GA, and appropriateness for GA) with refractive status in different age groups of Caucasian children.

\section{Materials and Methods}

This cross-sectional study included children aged 4 to 17 years who had been examined at the Department of Ophthalmology in 2013. The children with neurologic sequela such as mental retardation and cerebral palsy and those who had ocular diseases such as glaucoma, cataract, and history of treatment for retinopathy of prematurity and those who had undergone any ocular surgery were excluded. In addition, the children with missing data regarding birth parameters were also excluded. A total of 282 children were enrolled in the study. Verbal assent was obtained from all children. Written informed consent was taken from the parents of the 
TABLE 1: The mean age, birth weight, and gestational age distribution according to age groups and refractive status.

\begin{tabular}{lcccccccc}
\hline & & \multicolumn{2}{c}{ Age } & \multicolumn{3}{c}{ Birth weight (gram) } & \multicolumn{2}{c}{ Gestational age (week) } \\
& & $N$ & Mean & SD & Mean & SD & Mean & SD \\
\hline & $\leq 7$ & 106 & 6,29 &, 806 & 2422,36 & 1019,306 & 35,58 & 4,431 \\
Age groups (Patients) & $8-9$ & 53 & 8,44 &, 513 & 2624,34 & 838,278 & 37,25 & 3,524 \\
& $10-12$ & 77 & 10,91 &, 843 & 2865,58 & 782,759 & 38,44 & 2,208 \\
& $\geq 13$ & 46 & 13,67 & 1,223 & 3033,91 & 875,713 & 38,61 & 2,349 \\
& Total & 282 & 9,16 & 2,846 & 2681,10 & 930,792 & 37,17 & 3,690 \\
\hline \multirow{3}{*}{ Refractive status (Eyes) } & Myopia & 91 & 10,38 & 2,653 & 3019,89 & 799,106 & 38,23 & 2,617 \\
& Emmetropia & 372 & 9,20 & 2,849 & 2601,42 & 935,861 & 36,92 & 3,895 \\
& Hypermetropia & 101 & 7,92 & 2,493 & 2669,31 & 961,987 & 37,15 & 3,601 \\
& Total & 564 & 9,16 & 2,846 & 2681,10 & 930,792 & 37,17 & 3,690 \\
\hline
\end{tabular}

$N$ : number; SD: standard deviation.

children who were involved in the study. The study was in accordance with the standards of the local ethics committee and conformed to the tenets of the Declaration of Helsinki.

The parents of the children provided the information regarding BW and GA based on the child's hospital delivery record.

All children underwent complete ophthalmologic examination including measurement of Snellen visual acuity as decimals, refraction, and dilated funduscopy. For cycloplegia, cyclopentolate $0.85 \%$ and phenylephrine $1.5 \%$ were instilled. After 30 minutes, the cycloplegic refraction measurement was performed with an autorefractor (Topcon A6300, Topcon Corporation, Tokyo, Japan). A total of 3 measurements were taken for each eye. The average value was recorded and the refraction was expressed as spherical equivalent (SE). The SE is the sum of spherical value and half of the cylindrical value. The children were divided into three groups according to their refractive status: emmetropia, myopia, and hyperopia. Emmetropia was defined between -0.5 and $+0.5 \mathrm{D}$, myopia as less than -0.5 , and hyperopia as more than +0.5 , respectively. They were further divided into age groups: 4-7, 8-9, 1012 , and $>13$ years. Birth parameters as BW and GA were evaluated for each age group. They were also divided into small for gestational age (SGA), appropriate for gestational age (AGA), and large for gestational age (LGA) according to their birth weights for the gestational age. The international standardized average fetal growth tables were considered to calculate appropriateness for gestational age [17].

2.1. Statistical Analysis. For statistical analysis, SPSS 22 statistical program was used. Multinominal logistic regression analysis was used to evaluate the effect of BW, GA, and age at examination on refractive error. Pearson chi-square test was performed to compare qualitative data. The statistical significance was set at $P<0.01$ and $P<0.05$.

\section{Results}

The mean age of the children was $9.2 \pm 2.8$ (age range 4-17 years). Of 282 children, 155 were male (55\%) and 127 were female $(45 \%)$. The mean SE was $+0.3 \pm 1.7$ (range: $(-10.0)-$ $(+10.0)$ diopters $)$ and the mean Snellen visual acuity was
$0.9 \pm 0.1(0.2-1.0)$. The mean BW and GA were $2681.1 \pm$ 930.8 grams (750-5000 grams) and 37.2 \pm 3.7 weeks (25-42 weeks). The mean age, BW, and GA distribution according to age groups and refractive status are given in Table 1. According to multinominal logistic regression analysis, children with myopia were more likely to have higher BWs than emmetropic children (OR: 1.0, 95\% CI: 1.000-1.001, and $P=0.028)$. Myopia is also more likely to be found in older age groups than emmetropia (OR: 1.119, 95\% CI: $1.27-$ 1.219 , and $P=0.010$ ) and hypermetropia (OR: 1.39, 95\% CI: $1.236-1.565$, and $P<0.0001)$. Number of AGA, SGA, and LGA children and number of children under and over 2500 grams, according to refractive states in each age group, are given in Table 2. Emmetropic children aged between 4-7 and 8-9 years of age had significantly lower BWs under 2500 grams whereas myopic children aged between 4 and 7 years of age had significantly higher BWs over 2500 grams. The hypermetropes were found to be significantly SGA between 13 and 17 years of age.

\section{Discussion}

Birth weight, as one of the indicators of intrauterine development, may be associated with several systemic disorders in the long term [18]. Since it also affects the eye size, it may have an impact on refractive status or development of refractive error along with gestational age. Likewise, another parameter, appropriateness for gestational age, as SGA, AGA, and LGA may have an impact on refraction. Therefore, in our study, we also grouped the children as SGA, AGA, or LGA.

We found that children with myopia were more likely to have higher BWs than emmetropic children. Also, when the cut-off for birth weight is chosen as 2500 grams, the myopes had significantly higher BWs above 2500 grams than the others in children aged $\leq 7$. There are other studies that investigated the relation between birth parameters and refraction. A comprehensive study in 1413 Singapore Chinese children reported an association between birth size and ocular dimensions [14]. They did not show a relation between birth size and refraction. However, they included school children 7-9 years old only and fewer premature children. We had 282 children with a wider range of age. Another study on 


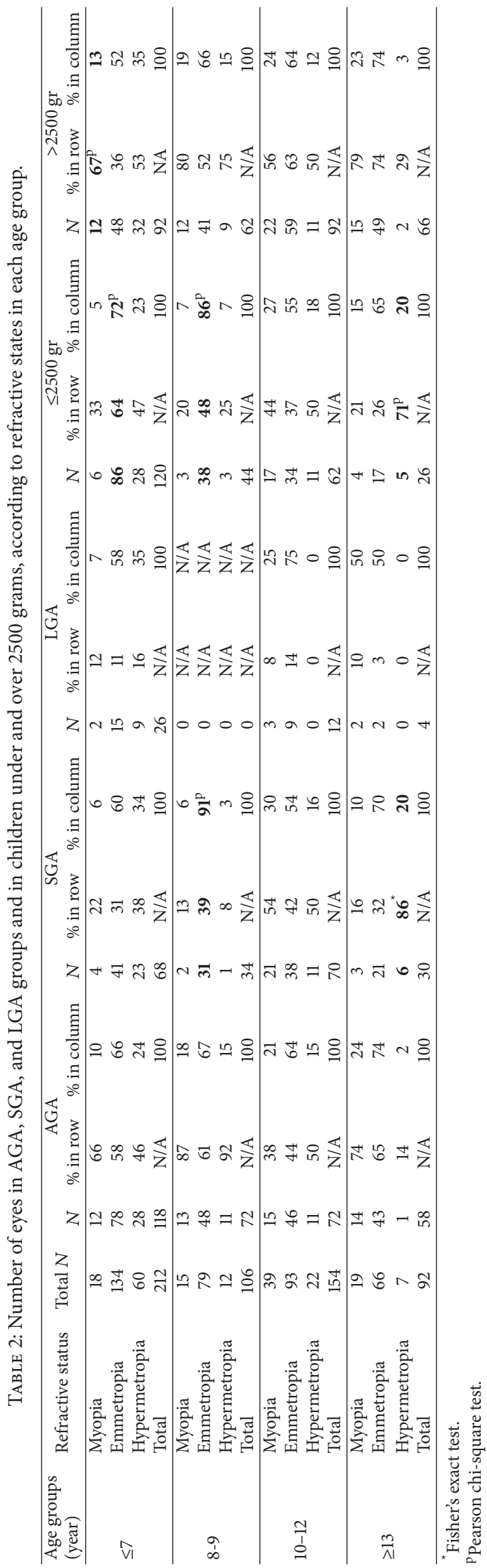


Australian children found that axial length and corneal radius were related to $\mathrm{BW}$, birth length, and head circumference but showed no trend or associations for spheric equivalent refractions in relation to birth parameters [15]. Apart from our study, they analysed children aged 6 years, in whom myopia can still develop, and excluded children who had been born before 36 weeks of gestational age. Similarly, a recent study also has reported that refraction is unrelated to birth size or gestational age in Swedish children aged 4-15 years [16], but this study comprised 143 children and did not include children born at $<35$ weeks' gestation.

Grjibovski et al. reported a significant association of BW with myopia in discordant dizygotic twin pairs [19]. On the other hand, another twin study with an age range of 18-86 years showed no association of BW with myopia [20]. But both studies showed that BW was not a major contributor to the discordance in myopia for monozygotic twin pairs. A cohort twin study comprising 1498 twins aged 5-80 years found no association between BW and refraction status. Lower BW tended to have shorter axial length and steeper corneas [21]. In our study, hypermetropia was more common in SGA children than in AGA or LGA children aged 13 years and older. These results may suggest that emmetropic SGA children in early ages tended to be hypermetropes in later ages. Our finding of increased hypermetropia in SGA is in accordance with the study of Lindqvist et al. [10]. They studied adolescents with very low birth weight $(<1500 \mathrm{~g})$, adolescents born at term but SGA, and concluded that being SGA may be a risk factor for hypermetropia development in adolescence, probably due to smaller eye size and other development arresting factors suggesting restricted fetal growth.

Prematurity has been associated with increased refractive errors including mainly myopia [22, 23]. However, it is also associated with hypermetropia [24]. Verma et al. also reported an inverse relationship between gestational age and incidence of refractive error [25]. In a cohort study comprising low birth weight children who were born preterm, the prevalence of all refractive errors was reported to be higher than the control group born at term who were involved in another study $[13,23]$. In our study, we also included both premature and SGA children and found that hypermetropia is associated with being SGA. Myopic children had higher BWs than emmetropes. The discrepancy between our study and the others may result from other factors that have a role in inducing myopia. Myopia has been shown to be affected by environmental factors, such as near work, educational access, and urbanization as well as genetic factors [26, 27].

To sum up, birth weight and appropriateness as birth parameters may have an impact on development of all types of refractive errors. Being SGA may be associated with hypermetropia. Therefore, delivery records of children as birth weight and gestational age may be important in determining the follow-up of them for refractive state changes.

\section{Conflict of Interests}

The authors do not have any conflict of interests.

\section{References}

[1] G. Holmström, M. El Azazi, and U. Kugelberg, "Ophthalmological long term follow up of preterm infants: a population based, prospective study of the refraction and its development," British Journal of Ophthalmology, vol. 82, no. 11, pp. 1265-1271, 1998.

[2] M. Y. Choi, I. K. Park, and Y. S. Yu, "Long term refractive outcome in eyes of preterm infants with and without retinopathy of prematurity: comparison of keratometric value, axial length, anterior chamber depth, and lens thickness," British Journal of Ophthalmology, vol. 84, no. 2, pp. 138-143, 2000.

[3] K. S. Mehra, B. B. Khare, and E. Vaithilingam, "Refraction in full term babies," The British Journal of Ophthalmology, vol. 49, pp. 276-277, 1965.

[4] A. Kuo, R. B. Sinatra, and S. P. Donahue, "Distribution of refractive error in healthy infants," Journal of AAPOS, vol. 7, no. 3, pp. 174-177, 2003.

[5] J. Wang, X. Ren, L. Shen, S. E. Yanni, J. N. Leffler, and E. E. Birch, "Development of refractive error in individual children with regressed retinopathy of prematurity," Investigative Ophthalmology and Visual Science, vol. 54, no. 9, pp. 6018-6024, 2013.

[6] R. M. Varghese, V. Sreenivas, J. M. Puliyel, and S. Varughese, "Refractive status at birth: its relation to newborn physical parameters at birth and gestational age," PLOS ONE, vol. 4, no. 2, Article ID e4469, 2009.

[7] Y. Ton, Y. S. Wysenbeek, and A. Spierer, "Refractive error in premature infants," Journal of American Association for Pediatric Ophthalmology and Strabismus, vol. 8, no. 6, pp. 534-538, 2004.

[8] G. E. Quinn, V. Dobson, M. X. Repka et al., "Development of myopia in infants with birth weights less than 1251 grams," Ophthalmology, vol. 99, no. 3, pp. 329-340, 1992.

[9] D. Robaei, A. Kifley, G. A. Gole, and P. Mitchell, "The impact of modest prematurity on visual function at age 6 years: findings from a population-based study," Archives of Ophthalmology, vol. 124 , no. 6, pp. 871-877, 2006.

[10] S. Lindqvist, T. Vik, M. S. Indredavik, and A.-M. Brubakk, "Visual acuity, contrast sensitivity, peripheral vision and refraction in low birthweight teenagers," Acta Ophthalmologica Scandinavica, vol. 85, no. 2, pp. 157-164, 2007.

[11] T.-C. Chen, T.-H. Tsai, Y.-F. Shih et al., "Long-term evaluation of refractive status and optical components in eyes of children born prematurely," Investigative Ophthalmology and Visual Science, vol. 51, no. 12, pp. 6140-6148, 2010.

[12] M. Modrzejewska, W. Grzesiak, D. Karczewicz, and D. Zaborski, "Refractive status and ocular axial length in preterm infants without retinopathy of prematurity with regard to birth weight and gestational age," Journal of Perinatal Medicine, vol. 38, no. 3, pp. 327-331, 2010.

[13] A. R. O’Connor, T. J. Stephenson, A. Johnson, M. J. Tobin, S. Ratib, and A. R. Fielder, "Change of refractive state and eye size in children of birth weight less than 1701 g," British Journal of Ophthalmology, vol. 90, no. 4, pp. 456-460, 2006.

[14] S.-M. Saw, L. Tong, K.-S. Chia et al., "The relation between birth size and the results of refractive error and biometry measurements in children," British Journal of Ophthalmology, vol. 88, no. 4, pp. 538-542, 2004.

[15] E. Ojaimi, D. Robaei, E. Rochtchina, K. A. Rose, I. G. Morgan, and P. Mitchell, "Impact of birth parameters on eye size in a population-based study of 6-year-old Australian children," American Journal of Ophthalmology, vol. 140, no. 3, pp. 535-537, 2005. 
[16] L. H. Raffa, A. Hellström, E. Aring, S. Andersson, and M. Andersson Grönlund, "Ocular dimensions in relation to auxological data in a sample of Swedish children aged 4-15 years," Acta Ophthalmologica, vol. 92, no. 7, pp. 682-688, 2014.

[17] T. R. Fenton and J. H. Kim, "A systematic review and metaanalysis to revise the Fenton growth chart for preterm infants," BMC Pediatrics, vol. 13, no. 1, article 59, 2013.

[18] K. Calkins and S. U. Devaskar, "Fetal origins of adult disease," Current Problems in Pediatric and Adolescent Health Care, vol. 41, no. 6, pp. 158-176, 2011.

[19] A. M. Grjibovski, J. R. Harris, and P. Magnus, "Birthweight and adult health in a population-based sample of Norwegian twins," Twin Research and Human Genetics, vol. 8, no. 2, pp. 148-155, 2005.

[20] M. Dirani, F. M. A. Islam, and P. N. Baird, "The role of birth weight in Myopia-the genes in myopia twin study," Ophthalmic Research, vol. 41, no. 3, pp. 154-159, 2009.

[21] C. Sun, A.-L. Ponsonby, S. A. Brown et al., "Associations of birth weight with ocular biometry, refraction, and glaucomatous endophenotypes: the australian twins eye study," American Journal of Ophthalmology, vol. 150, no. 6, pp. 909-916, 2010.

[22] B. A. Darlow, R. S. Clemett, L. J. Horwood, and N. Mogridge, "Prospective study of New Zealand infants with birth weight less than $1500 \mathrm{~g}$ and screened for retinopathy of prematurity: visual outcome at age 7-8 years," British Journal of Ophthalmology, vol. 81, no. 11, pp. 935-940, 1997.

[23] E. K. Larsson, A. C. Rydberg, and G. E. Holmström, "A population-based study of the refractive outcome in 10-year-old preterm and full-term children," Archives of Ophthalmology, vol. 121, no. 10, pp. 1430-1436, 2003.

[24] K. J. Saunders, D. L. McCulloch, A. J. Shepherd, and A. G. Wilkinson, "Emmetropisation following preterm birth," British Journal of Ophthalmology, vol. 86, no. 9, pp. 1035-1040, 2002.

[25] M. Verma, J. Chhatwal, S. Jaison, S. Thomas, and R. Daniel, "Refractive errors in preterm babies," Indian Pediatrics, vol. 31, no. 10, pp. 1183-1186, 1994.

[26] S.-M. Saw, S.-B. Tan, D. Fung et al., "IQ and the association with myopia in children," Investigative Ophthalmology and Visual Science, vol. 45, no. 9, pp. 2943-2948, 2004.

[27] I. Morgan and K. Rose, "How genetic is school myopia?" Progress in Retinal and Eye Research, vol. 24, no. 1, pp. 1-38, 2005. 


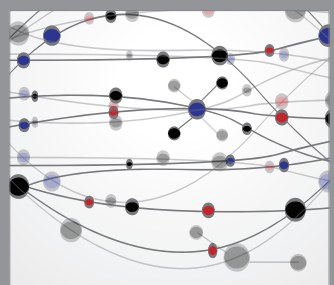

The Scientific World Journal
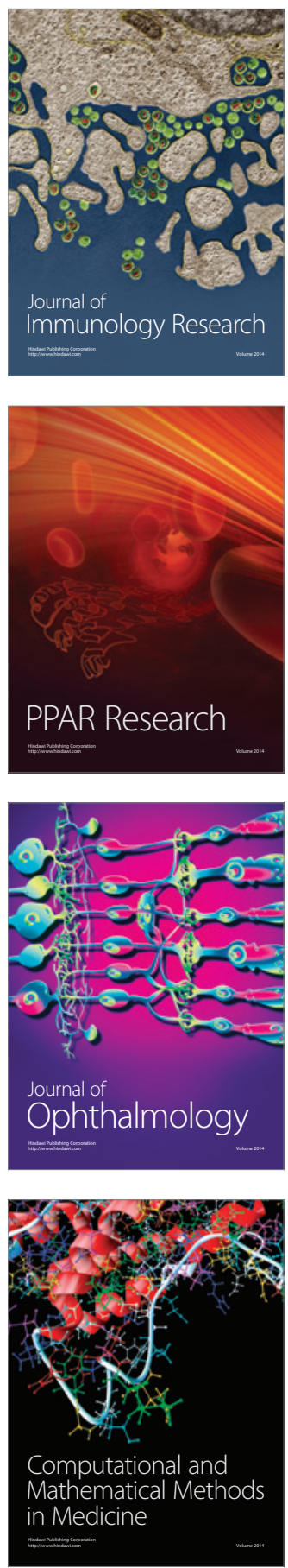

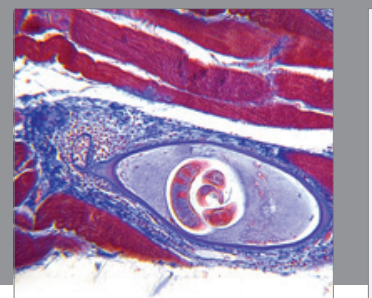

Gastroenterology

Research and Practice
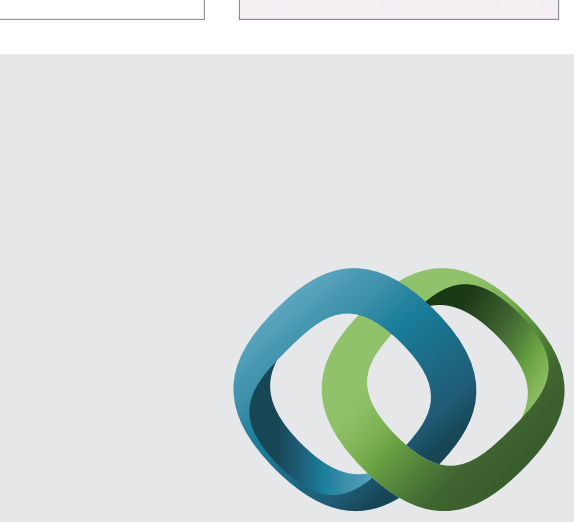

\section{Hindawi}

Submit your manuscripts at

http://www.hindawi.com
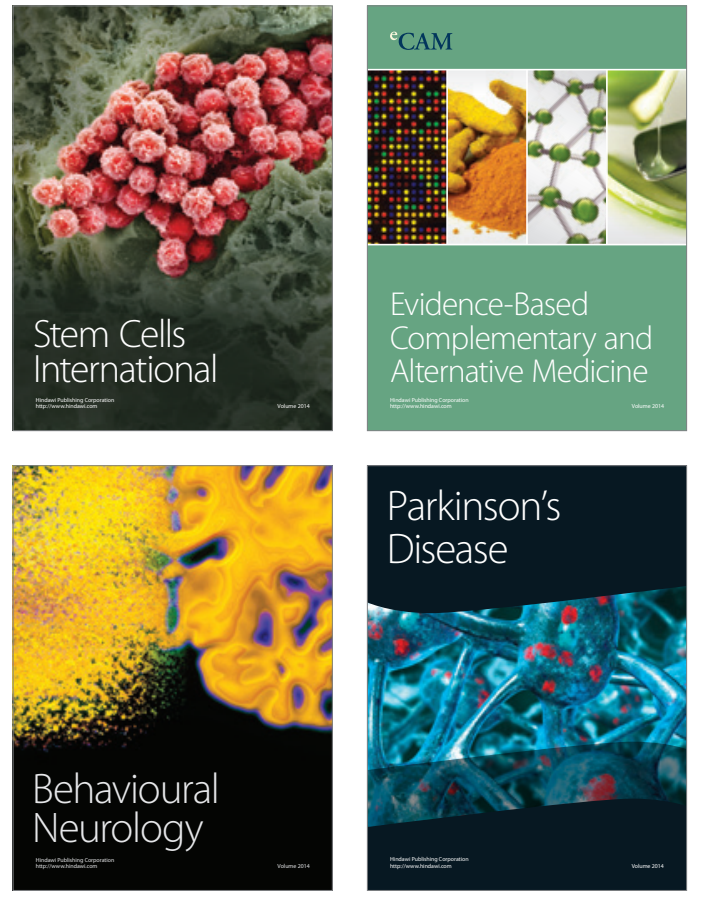
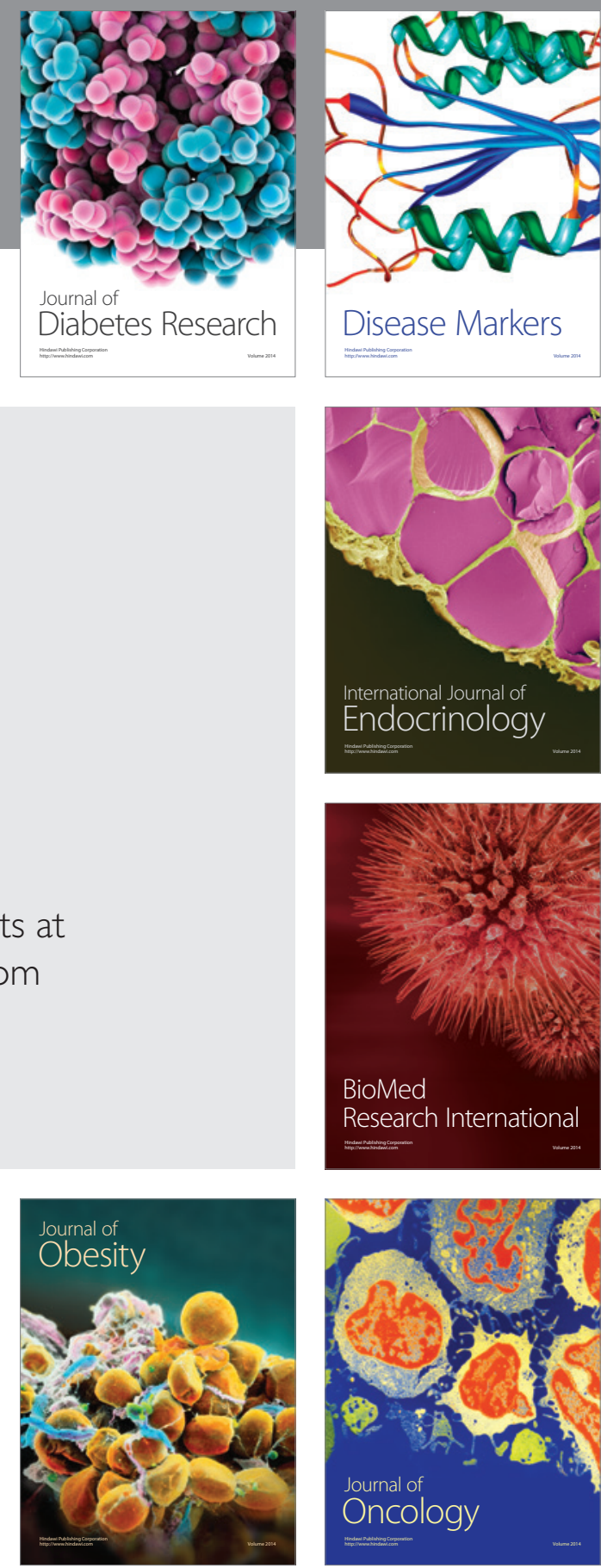

Disease Markers
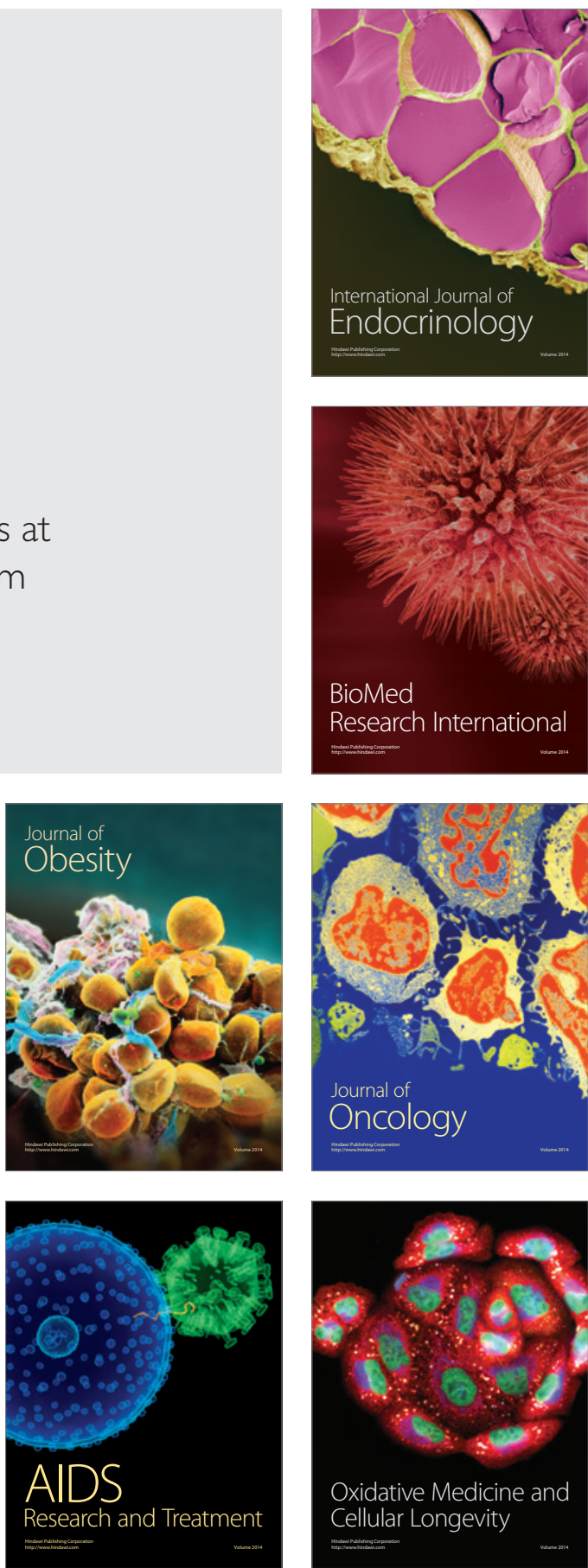